\title{
O MASSACRE: A VIOLÊNCIA REPRESENTADA NO JORNALISMO LITERÁRIO BRASILEIRO
}

\section{LA MASACRE: LA VIOLENCIA REPRESENTADA EN EL PERIODISMO LITERARIO BRASILEÑO}

\section{THE MASSACRE: THE VIOLENCE REPRESENTED IN THE BRAZILIAN LITERARY JOURNALISM}

\author{
Laísa Veroneze Bisol \\ Universidade de Santiago de Compostela, Espanha \\ laisabisol1@gmail.com \\ Xosé Antonio Neira Cruz \\ Universidade de Santiago de Compostela, Espanha \\ neira.cruz@usc.es \\ Lizandro Carlos Calegari \\ Universidade Federal de Santa Maria, Brasil \\ lizandro.calegari@yahoo.com.br
}

\begin{abstract}
Resumo:
O jornalismo literário assume uma importante função ao representar temas sociais que são motivo de reflexão. Uma dessas temáticas é a violência, que está presente de forma profunda no território brasileiro e que acomete determinados grupos de maneira mais intensa. Sendo assim, este estudo investiga o romance-reportagem $O$ massacre, de Eric Nepomuceno, que aborda o modo como integrantes do Movimento dos Trabalhadores Sem Terra (MST) sofrem ações de crueldade. O percurso da escrita tem como base a metodologia da literatura comparada e é constituído por pesquisa bibliográfica em consonância com análise interpretativa. Os resultados indicam que o jornalismo literário brasileiro, a partir da obra estudada, representa os acontecimentos violentos atribuindo voz e identidade aos sujeitos, estruturando uma narrativa com detalhamento e condução à criticidade.
\end{abstract}

Palavras-chave: jornalismo literário; O massacre, violência, MST

\begin{abstract}
:
Literary journalism has an important role in representing social issues which motivates broad reflections. One of these themes is violence, which is deepley present in Brazilian territory and affects certain groups more intensely. Thus, this study investigates Eric Nepomuceno's novel-report $O$ massacre, which addresses how members of Landless Workers Movement (MST) suffer cruelty. The methodology is based on comparative literature and consists of bibliographical research along with interpretive analysis. The results indicate that Brazilian literary journalism, considering the book being studied, represents violent events, giving voice and identity to the subjects, structuring a narrative with details and leading to criticality.
\end{abstract}


Keywords: literary journalism; O massacre; violence; MST

Resumen: El periodismo literario tiene un papel importante en la representación de cuestiones sociales que son motivo de reflexión. Uno de estos temas es la violencia, que está profundamente presente en el territorio brasileño y que afecta con mayor intensidad a determinados grupos. Así, este estudio investiga la novela-reportaje $O$ massacre, de Eric Nepomuceno, que aborda cómo los miembros del Movimiento de Trabajadores Sin Tierra (MST) sufren crueldad. El curso de redacción se basa en la metodología de la literatura comparada y consiste en la investigación bibliográfica en línea con el análisis interpretativa. Los resultados indican que el periodismo literario brasileño, a partir del trabajo estudiado, representa los hechos violentos, dando voz e identidad a los sujetos, estructurando una narrativa con detalles y conduciendo a la criticidad.

Palabras clave: periodismo literario; O massacre; violencia; MST

Recibido: 21de abril de 2021

Aceptado: 09 de junio de 2021

\section{Literatura e jornalismo}

Literatura e jornalismo são áreas convergentes. Com a expressão escrita, é possível representar o mundo em suas mais diferentes facetas. Nesse ínterim, convém salientar que, embora cada forma de narrativa tenha suas especificidades - o jornalismo com textos noticiosos e a literatura com ficção -, são áreas que há muito tempo se inter-relacionam, especialmente considerando o gênero romance-reportagem. Sendo assim, temos o jornalismo literário, que é capaz de representar versões de realidades por meio de uma linguagem que possui mais poeticidade, detalhamento e aprofundamento, tornando o relato mais humanizado do que aquele que costumamos observar no noticiário do cotidiano.

Tom Wolfe explica os caminhos do surgimento dessa linguagem. Nos anos 1950, era preciso escolher entre ser jornalista ou ser romancista, não sendo possível unir informação e literariedade. No entanto, conforme o autor, a partir dos anos 1960, uma nova ideia começa a ser descoberta, o jornalismo escrito em formato de romance.

O termo New Journalism (Novo Jornalismo) surge, nesse período, nos Estados Unidos, para designar uma nova prática textual oriunda de um momento político, social e cultural, em que um novo formato de texto jornalístico aparece, desvencilhando-se de 
técnicas básicas como lead, pirâmide invertida e ideia de objetividade. Segundo Wolfe (44), enquanto grande parte dos repórteres, concorrendo entre si, corria atrás do "furo" jornalístico, ou seja, de pautas inéditas e, geralmente, de grande impacto, um outro grupo de jornalistas passou a dedicar-se a "reportagens especiais", mais aprofundadas, abrangendo inúmeros detalhes. A ideia de Novo Jornalismo ganhou força com a publicação do livro A sangue frio (1966), de Truman Capote, romancista que, segundo Wolfe, estava com a carreira um pouco parada até a publicação dessa obra que é considerada como fundadora do jornalismo literário.

O jornalismo literário chega como uma forma de aprofundamento dos acontecimentos já que muitos dos episódios que permeiam a vida humana, por vezes, caem no esquecimento. Ao transformar situações históricas em relatos mais aprofundados, os autores das obras de jornalismo literário contribuem para que os assuntos importantes continuem fazendo parte do imaginário social. Em geral, são transformados em romances-reportagens aqueles temas que merecem estar sempre na linha de reflexão, como é o caso da temática da violência, por exemplo.

Felipe Pena afirma que o jornalista literário, longe de ignorar aquilo que faz parte do jornalismo diário, desenvolve essas técnicas narrativas, construindo novas estratégias que mantêm, principalmente, princípios como rigorosa apuração, ética, observação e clareza. A maneira como o jornalista se apropria dos fatos para contá-los aos leitores, interpretando histórias, pode ser uma das características que tornam uma reportagem ou um romance-reportagem mais completos e interessantes do que uma matéria meramente informativa.

Ainda na busca por compreender as características do romance-reportagem, apresentamos a perspectiva de Edvaldo Pereira Lima, que aponta uma diferenciação entre essas obras e outros romances. A primeira delas diz respeito ao conteúdo, já que, conforme o autor, as abordagens dos livros-reportagens correspondem ao factual. Já a segunda tem ligação com o tratamento, ou seja, a linguagem utilizada, que é a jornalística. A terceira leva em conta a função, isso quer dizer, o livro-reportagem cumpriria as finalidades do jornalismo de informar, explicar e orientar, por exemplo.

Acrescentamos aqui a ideia de Chillón, uma vez que o autor afirma que os textos podem traduzir as experiências sensitivas dos sujeitos. O jornalismo literário, a maneira 
Dossier. Laísa Veroneze Bisol, Xosé Antonio Neira Cruz, Lizandro Carlos Calegari. “O Massacre: a violência representada no jornalismo literário brasileiro"

como a narrativa se constrói, permite, em maior medida, a expressão das experiências dos sujeitos que fazem parte da história narrada. Nesse tipo de texto, há uma preocupação com a demonstração mais minuciosa de quem é o indivíduo e suas particularidades diante daquele contexto.

Nessa direção, buscamos analisar, neste artigo, de que maneira um romancereportagem pode representar uma temática de grande importância, como é o caso da violência. Para isso, nosso objeto de estudo é a obra $O$ massacre - Eldorado do Carajás: uma história de impunidade, de Eric Nepomuceno. Desenvolvemos a investigação por meio de pesquisa bibliográfica em consonância com a análise interpretativa, tendo como base os pressupostos metodológicos do comparatismo.

\section{A violência e o romance-reportagem}

Seja física, simbólica, institucionalizada ou não, a violência assume um papel junto à humanidade. Na perspectiva de Sigmund Freud, os conflitos humanos geralmente são resolvidos através da violência, e um rápido olhar acerca da história da humanidade revela uma imensidão de conflitos entre duas ou mais comunidades, unidades, cidades, grupos étnicos, nações, impérios e outros, mas quase sempre com a força advinda das armas. Ainda conforme Freud, os seres humanos podem ser incitados à guerra por diferentes motivos, sejam eles nobres ou vis. Contudo, ressalta que, entre esses motivos, “está certamente o desejo da agressão e destruição: as incontáveis crueldades que encontramos na história e em nossa vida de todos os dias atestam a sua existência e a sua força" (Freud 39).

A brutalidade que espanta ou que, por ser tão explícita e recorrente, causa passividade, é explicada por Jaime Ginzburg como parte da construção histórica, causada por seres humanos e suas motivações, embora o crítico afirme não haver justificativa para atos violentos. "A história do Brasil é constituída de modos violentos, desde a colonização, a escravidão, passando pelas ditaduras até o presente" (Ginzburg 9), ou seja, trata-se de uma violência enraizada na estrutura social.

Hannah Arendt (6) afirma que "ninguém que se dedique à meditação sobre a história e a política consegue se manter ignorante do enorme papel que a violência 
desempenhou sempre nas atividades humanas" e chama a atenção para o fato de que surpreende que tão raro a violência tenha se tornado objeto de consideração.

De acordo com os autores Aguinaldo de Bastos, Alexandre Marques Cabral e Jonas Rezende, a violência não é fruto da animalidade, mas da própria racionalidade humana. "É que no homem tudo o que ele é e faz, sente e pensa, compreende e experimenta já é marcado pela sua humanidade. É como humano que o homem é violento" (Bastos et al. 113). Os pesquisadores, entre outras justificativas, destacam que a história da humanidade caminha em conjunto com a história da crueldade, já que sofrer e fazer sofrer é parte estruturadora do processo histórico do ocidente. Ressaltam, ainda, que os seres humanos são vítimas, mas também são culpados pela perpetuação dessa lógica estruturadora violenta.

Bastos, Cabral e Rezende elucidam, citando as ideias de Erich Fromm, as motivações inconscientes de diferentes tipos de violências, excetuando as de cunho patológico. O primeiro tipo refere-se à "violência recreativa", em que não há motivação por ódio e que só há morte, se acontecer algo fora do planejado. Ainda que haja algum desejo inconsciente por destruição, a motivação, aqui, refere-se à exposição de habilidades, portanto, esse primeiro tipo de violência refere-se, por exemplo, a jogos, como os realizados por tribos primitivas. O segundo tipo mencionado pelos autores trata da "violência reativa", que teria como intuito defender a vida, a liberdade, a dignidade ou a propriedade, tendo como objetivo preservar e não destruir. A terceira forma seria a "violência vingativa"; nesse aspecto, os autores retomam a ideia de Fromm que a caracteriza com a finalidade de, de forma mágica, desfazer outro ato violento. Trata-se de uma tentativa de retribuir em igual medida um sofrimento, através de punição. Os estudiosos expõem também o quarto tipo, a "violência compensatória", em que, para compensar uma impotência diante do mundo ou de alguns aspectos, os indivíduos desenvolvem comportamentos violentos, não com o objetivo de fazer sofrer, mas de exercer domínio sobre o outro. Por fim, a quinta forma apresentada é a "sede de sangue", mais comum nas sociedades primitivas, mas que atribui ao sujeito agressor a sensação de vida e fortaleza diante de outros. Seriam ações de crueldade não por amor à destruição, mas como afirmação de si mesmo. 
Dossier. Laísa Veroneze Bisol, Xosé Antonio Neira Cruz, Lizandro Carlos Calegari. “O Massacre: a violência representada no jornalismo literário brasileiro"

A esses tipos de violência mencionados, acrescentamos ainda um sexto, a "violência por circunstância". Considerando especialmente aqui o contexto social e cultural brasileiro - uma vez que os autores também afirmam que a condição da violência pode ser interpretada diferentemente dependendo da cultura a qual se insere -, é possível observar que há uma violência quase que naturalizada, que faz parte do meio.

Ainda na ideia de categorizar a violência, algumas das formas são citadas por Ginzburg que as expõe como sendo simbólicas, psicológicas, por intimidação, humilhação, remetendo, ainda, à desumanização e à hostilidade: "trata-se de uma palavra que é chamada para falar frequentemente de situações difíceis de descrever, de extremo horror, de níveis de sofrimento que não deveriam existir" (Ginzburg 10), mas que acabam se tornando comuns entre os indivíduos. E o mesmo autor questiona: "por que isso é um fenômeno comum?" (Ginzburg 11). Na medida em que já está institucionalizada como parte da estrutura social, a violência acaba por não causar mais estranhamento, é como se a humanidade ficasse alheia a essa discussão, uma vez que esses fenômenos teriam se tornado, inexplicavelmente, inerentes à humanidade. Sendo assim, é cada vez mais necessário abordar esse tema sob uma perspectiva aprofundada e com vistas à humanização, como é o caso dos romances-reportagens.

Embora os veículos de comunicação brasileiros apresentem, em geral, a temática de maneira descontextualizada e sensacionalista, existem as exceções que se comprometem em oferecer conteúdo de qualidade e munido de possíveis soluções. Compreendemos, assim, que deve importar não somente o motivo da divulgação de acontecimentos violentos, que também percorre o caminho do fazer conhecer, mas, principalmente, a maneira como essa violência é abordada em narrativas de cunho nãoficcional, especialmente quando a observação consiste em uma obra que supera o jornalismo diário para unir-se com outra forma de narração, como é o caso dos romancesreportagens. Diante disso, se há um jornalismo que divulga os fatos de forma a fazer refletir, então é de fato possível que, também, através da narrativa não-ficcional, esses temas possam humanizar, dependendo do modo como são abordados.

A partir do entendimento acerca da temática da violência exposto até aqui, propomos a ideia de que as relações de violência estão estreitamente interligadas com a questão do poder e da dominação. Isso porque um ato de crueldade pressupõe um sujeito 
que o comete e outro acometido por ele, ou seja, há um lado que se sobrepõe em detrimento de outro.

Segundo o filósofo Michel Foucault as relações de poder só acontecem quando os indivíduos são livres, ou seja, quando ainda há a possibilidade de resistência. Todavia, se um dos lados estiver totalmente à disposição do outro, como se fosse um objeto para que seja exercida uma violência ilimitada, o que ocorre não é uma relação de poder, mas de dominação. Tendo isso em vista, a concepção de violência se dá pela negação total do outro.

Slavoj Žižek indica uma relação entre violência e poder, afirmando que atos violentos ultrapassam as ações de crueldade, sendo, para além disso, problemas relacionados a ideologias, interligados, por exemplo, com o poder do Estado ou econômico.

Thompson, ao discutir a questão social no âmbito da comunicação, afirma que um conjunto de circunstâncias conferem aos indivíduos diferentes oportunidades e inclinações e, citando Pierre Bourdieu, ele as nomeia como "campos de interação" em que os indivíduos se situam em diversas posições, conforme a quantidade e o tipo de recursos disponíveis a cada um. "Em alguns casos estas posições, quando institucionalizadas, adquirem uma certa estabilidade - isto é, tornam-se parte de um conjunto relativamente estável de regras, recursos e relações sociais” (Thompson 37).

Para explanar sobre as diferentes formas de atuação desse poder, Thompson realiza uma pesquisa em diversos autores, entre os quais Michael Mann e, aliando à sua própria perspectiva em torno do tema, distingue quatro principais tipos de poder, sendo eles o econômico, o político, o coercitivo e o simbólico. O econômico diz respeito a recursos materiais e financeiros, ou seja, de acordo com o que um indivíduo ou uma empresa consegue acumular, se estabelece seu posicionamento, aumentando o poder econômico. Já o político se refere ao recurso da autoridade derivado de atividades de coordenação de pessoas e regulamentações de padrões. "Todos os estados ou instituições paraestatais são essencialmente sistemas de autoridade. Implicam um complexo sistema de regras e procedimentos que autorizam certos indivíduos a agirem de determinadas maneiras" (Thompson 40). O poder coercitivo, por outro lado, possui como recurso a força física e armada - e, por isso, algumas vezes, liga-se ao político. Trata-se de uma 
forma de poder que se relaciona a instituições militares, por exemplo. O poder simbólico, para Thompson (42), diz respeito a recursos de informação e comunicação, ou seja, está atrelado a instituições culturais como igrejas, escolas, universidades, mídia, entre outras: "na produção de formas simbólicas, os indivíduos se servem destas e de outras fontes para realizar ações que possam intervir no curso dos acontecimentos com consequências as mais diversas". Junto dessas, o pesquisador destaca que o poder simbólico pode provocar reações, liderar respostas e decisões, induzir a crenças, apoiar processos, etc.

Embora os quatro poderes expostos sejam institucionalizados, ou seja, exercidos por grupos ou por organizações reconhecidas, compreendemos que eles podem ser aplicáveis também de outra maneira quando consideradas as relações de dominação e, mais especialmente, se os pusermos no âmbito da violência. Ou seja, a força econômica, política, coercitiva ou simbólica, enquanto meio de dominação, também pode ser empregada sem essa mediação institucional e se fazer presente entre sujeitos. Isso porque a violência, em nossa sociedade, decorre também dessas possibilidades.

Ações violentas são a todo instante representadas por meio de diferentes meios de comunicação e, pela grande quantidade de informações e, também, até mesmo a forma quase natural como as notícias costumam ser veiculadas, são fatores que podem estimular a passividade diante dos acontecimentos expostos. Entretanto, ao abordar essa temática a partir de uma representação que se dá por uma narrativa diferenciada da mídia cotidiana, como é o caso do romance-reportagem, que une a informação com elementos que conferem literariedade ao texto, o senso reflexivo pode ser despertado nos leitores de forma mais eficaz, mesmo que ainda se trate de um recorte da realidade. A leitura imersiva, que dispende tempo para compreensão, interpretação dos detalhes e, quase inevitavelmente, a composição de ponderações a respeito do que foi lido, desperta um deslocamento, ou seja, dificilmente o indivíduo ficará passivo diante do que leu, como ocorre quando as informações são rápidas e instantâneas. De outro lado, quem escreve a obra também dedica mais esforços a essa representação, atribuindo voz a muitos sujeitos e expondo uma vasta pesquisa a respeito daquilo que escreve.

A partir dessas ponderações, na sequência deste estudo, expomos o modo como a violência e as relações de dominação e poder são representadas na obra de jornalismo literário brasileiro $O$ massacre. 


\section{A violência representada em $O$ massacre}

O episódio que ficou conhecido mundialmente como "massacre" é o tema central da obra de Eric Nepomuceno, intitulada como O massacre - Eldorado do Carajás: uma história de impunidade. $\mathrm{O}$ termo se refere ao momento em que integrantes do Movimento dos Trabalhadores Rurais Sem Terra (MST) foram mortos em uma ação policial ocorrida na denominada Curva do S, no Estado do Pará, em 17 de abril de 1996.

O livro, que retoma esse acontecimento, foi publicado em 2007 pela Editora Planeta e foi condecorado, em 2008, como o segundo melhor livro na categoria "Reportagem" do Prêmio Jabuti, a maior premiação literária brasileira. Em 2019, ele foi atualizado e publicado pela Editora Record. A primeira edição, analisada neste estudo, possui 214 páginas divididas em cinco capítulos.

Além da linguagem escrita, a obra apresenta fotografias muito expressivas registradas por Sebastião Salgado. São imagens em preto e branco que compõem a narrativa auxiliando a contar a história retratada. Essas cores são características do livro, que possui um apelo estético bastante interessante, já que, além da composição fotográfica, o início dos capítulos é marcado por páginas em cor preta. Essas composições de cores frias ajudam o leitor a imergir no contexto apresentado, já que a violência, a morte e a impunidade são representadas de maneira veemente.

A obra de Nepomuceno retrata aspectos acerca de um dos grupos que muito sofre com as relações violentas e de poder no Brasil, os trabalhadores rurais sem terra. No país, esse é mais um tema de vasta discussão e divergência de pensamentos: de um lado, grandes fazendeiros que possuem terras pouco aproveitadas, de outro, trabalhadores sem terra que buscam um espaço para trabalharem e sobreviverem. Porém, o contexto não é tão simples como pode sugerir um primeiro momento, já que o próprio MST (Movimento dos Trabalhadores Rurais Sem Terra), por muitas vezes, se divide por questões éticas e ideológicas. Os mais diversos lados dessa história são abordados por Nepomuceno a partir de uma vasta pesquisa que incluiu documentos, entrevistas e uma detalhada apuração que levou três anos para ser concluída em forma de romance-reportagem.

Nepomuceno é natural de São Paulo, nasceu em 1948 e começou a trabalhar como jornalista em 1965. Atuou no Jornal da Tarde e na revista Veja, também foi correspondente internacional. Ele realizou a cobertura jornalística dos golpes de Estado na Argentina e no 
Dossier. Laísa Veroneze Bisol, Xosé Antonio Neira Cruz, Lizandro Carlos Calegari. “O Massacre: a violência representada no jornalismo literário brasileiro"

Uruguai, e das guerras civis em El Salvador, Guatemala e Nicarágua. O autor descreve o caminho de pesquisa para a escrita de $O$ massacre:

Trabalhei neste livro entre fevereiro de 2004 e junho de 2007. Entrevistei 32 pessoas, algumas delas várias vezes, em São Paulo, Rio de Janeiro, em Brasília, Belém do Pará, Marabá, Eldorado do Carajás e Parauapebas. Essas conversas resultaram em cerca de 54 horas de gravações, além de três cadernetas repletas de anotações. Li, da primeira à última, as quase mil páginas que integram os dois inquéritos - o da Polícia Militar e o da Polícia Civil - que investigaram o caso. Perdi a conta do número de documentos acadêmicos, análises, ensaios e material de imprensa que consultei. Em 2005 viajei ao Pará, percorri acampamentos do MST e visitei assentamentos rurais da região de Marabá, passando por Eldorado do Carajás, Curionópolis e Parauapebas. Conversei longamente com advogados, promotores e assistentes de acusação que participaram dos julgamentos dos policiais militares. Conversei com políticos paraenses, alguns deles bastante próximos ao ex-governador Almir Gabriel. Ouvi, de veteranos jornalistas, histórias sobre o poder político no Pará. E, claro, fiz prolongadas entrevistas com várias testemunhas do massacre - os sobreviventes. (Nepomuceno 15)

O percurso de apuração descrito por Nepomuceno não apenas indica o processo para chegar ao texto final, como conduz à ideia de que a obra em questão não dá vasão à superficialidade, ao contrário, os anos de investigação, nos mais diferentes meios de informação, originaram um livro que abarca a profundidade do que ocorreu no dia $17 \mathrm{de}$ abril de 1996.

Toda a narrativa é desenvolvida a partir de muitos dados, sejam eles numéricos ou decorrentes de pesquisa documental e entrevistas. Isso tudo aliado às percepções do autor e a partir de uma descrição que utiliza a linguagem literária, com exposição de detalhes e reconstrução humanizada dos acontecimentos. Esse aspecto pode ser observado, por exemplo, quando Nepomuceno visita e descreve a Vila 17 de Abril, onde vivem os sobreviventes do massacre:

O caminho da vila é feito de pequenas elevações, quase colinas, onde campos verdes, parecendo pastos de gado escasso, surgem salpicados por troncos negros, erguidos contra o nada: são os restos de antigas castanheiras, que pontilham toda a paisagem da região com suas formas esguias, escuras e abandonadas. Há muitos troncos robustos, todos vítimas do fogo. Também ali, outrora, muito antes da chegada dos atuais 
moradores, havia um enorme bosque de castanheiras, um castanhal sem fim. (Nepomuceno 63)

A caracterização do espaço conduz o leitor a se inserir nesse contexto através da visualização do ambiente, já que o autor não apenas menciona superficialmente como é aquele lugar, mas descreve, de maneira pormenorizada, a cenografia que o compõe. Assim como a ambientação da pequena localidade, outros momentos são descritos de modo a conduzir o leitor a imaginar a situação enfrentada pelos envolvidos, inclusive a narração referente à realidade dos sujeitos acometidos pelo massacre.

É possível observar um desses exemplos no trecho em que Nepomuceno (69) descreve a vivência de João Rodrigues, que tinha 21 anos quando levou um tiro no peito, em razão do ocorrido na Curva do S, no dia do massacre. "A bala nunca foi retirada. Quando vai trabalhar no lote que a família ganhou no assentamento, o esforço faz com que o braço fique dormente, enquanto o peito começa a doer. Vive tomando, todo dia, pesados anti-inflamatórios". Ao atribuir identidade ao sujeito por meio do seu nome e, principalmente, ao citar sua realidade em consonância com a de sua família e trabalho, o autor apresenta uma narrativa permeada pela sensibilidade, que é capaz de despertar o senso de empatia, considerando que, para além de um número determinado de mortos e feridos, existem indivíduos que ainda enfrentam lutas diárias pelo que ocorreu no dia do massacre.

A representação pormenorizada e munida de uma evidente aproximação com os indivíduos envolvidos, juntamente com a busca por resgatar e resguardar a memória dos acontecimentos, é evidenciada através das narrativas de jornalismo literário e está presente também na obra de Nepomuceno. $\mathrm{O}$ autor deixa isso claro nas primeiras páginas de seu texto:

Este livro, enfim, não foi escrito com o objetivo de fazer revelações drásticas: trata apenas de reconstruir uma tragédia. Mais do que poder revelar, quer recordar - soprar as brasas da memória para impedir que se tornem cinzas mortas. Ele foi escrito para lembrar que esta história pertence a um passado que permanece, intacto, no presente de outros milhares de brasileiros que vivem a esperança cotidiana de conquistar o seu pequeno universo particular - um pequeno pedaço de terra. (Nepomuceno 19, grifos do autor) 
Dossier. Laísa Veroneze Bisol, Xosé Antonio Neira Cruz, Lizandro Carlos Calegari. “O Massacre: a violência representada no jornalismo literário brasileiro"

Essa percepção demonstra um dos grandes objetivos do romance-reportagem, que é justamente trazer presente um fato que, depois de alguns anos, poderia ter caído no esquecimento da sociedade, já que a mídia tradicional cotidiana tem como prioridade as notícias inéditas e imediatas obedecendo, assim, aos critérios de noticiabilidade. No entanto, para aqueles que ainda vivenciam as dores de suas perdas ou dos ferimentos físicos, o acontecimento segue bastante presente na memória.

Ademais, o excerto apresentado introduz duas questões bastante pertinentes que foram abordadas de maneira acurada durante a narrativa: a situação do Estado do Pará dentro do contexto brasileiro e, também, o cenário envolvendo os trabalhadores rurais que buscam terras para trabalhar e prover o sustento de suas famílias.

No Brasil, a chamada Amazônia Legal é fracionada em duas partes, a Ocidental, que compõe os Estados do Amazonas, Acre, Rondônia e Roraima, e a Oriental, composta pelos Estados do Pará, Maranhão, Amapá, Tocantins e Mato Grosso. Segundo relata Nepomuceno (56), "a Amazônia brasileira é terra de ninguém, de muitos projetos ocos e palavras ao léu, de omissões abjetas e criminosas". O autor segue afirmando que o que se pode visualizar no interior do Pará são cemitérios a céu aberto, troncos espalhados entre pastos vazios, capinzais e "palitos negros que se levantam como testemunhas caladas de um drama que não merece atenção de ninguém".

Naquele Estado, existem grandes fazendeiros que detêm uma vastidão de espaço, enquanto outros reivindicam por trabalho, já que muitas terras de propriedade privada estão ociosas, e grande parte delas possui registros questionáveis, já que existem terras registradas, inclusive, em nome de pessoas que sequer existem legalmente. É, portanto, conforme descrita na obra, uma terra permeada por disputas, com titulação de terras não suficientemente clara e com a riqueza nas mãos de poucos enquanto uma parte da população vive na linha da miséria.

A violência no contexto paraense envolve, sobretudo, uma questão de poder. Um exemplo disso é citado pelo autor quando relata o caso de um ex-prefeito da cidade de Marabá, Osvaldo Mutran. Conhecido como Vavá, foi nomeado prefeito no tempo da ditadura, sem ter obtido votos. Nepomuceno (31) conta: "a fama veio depois de ter matado um fiscal da Receita Federal que não concordou em deixá-lo passar por uma barreira de controle com gado sem registro", e, ainda, "em 2002, Vavá deu um tiro na cabeça de um 
menino que brincava na frente da sua casa em Marabá”. O político e empresário chegou a ser preso e depois foi inocentado. Em 2005, conforme relata o autor, aguardava por um novo julgamento, em liberdade. Com esse relato, é possível perceber de forma clara por que a impunidade é abordada de modo tão saliente na obra analisada. É como se aqueles que detêm o poder econômico e social estivessem também acima de qualquer lei, quando considerado o abismo entre a riqueza e a miséria daquele Estado.

Corroborando esse argumento, a narrativa também apresenta um fato bastante chocante naquele Estado: a prática do trabalho escravo, que chega a ser um fato comum e que ocorre em menores proporções também em outros espaços nacionais. Porém, de acordo com o exposto por Nepomuceno (25), nenhum outro Estado brasileiro possui tantos casos de trabalho escravo como no Pará e em "nenhum outro lugar do mapa do país se somam tantas mortes por causa de terra”. Diante disso, a obra recorda a história oficial do Brasil que aponta que a escravidão foi abolida em 13 de maio de 1888, o penúltimo país a tomar essa medida em todo o mundo, sendo Marrocos o último. Porém, "alguns dos grandes latifundiários e os que se instalaram à margem da lei nas terras do Pará, em todo caso, não levam muito a sério a história e suas datas. Há sempre braços disponíveis buscando um meio de sobreviver" (Nepomuceno 25). No final de 2006, segundo a apuração feita pelo jornalista, 238 empregadores mantinham pessoas trabalhando em regime de escravidão em 13 Estados brasileiros.

O que ocorre, em especial no Pará, é um sistema em que um intermediário dos proprietários das fazendas, nomeado de "gato", contrata os indivíduos, retém seus documentos, quando possuem, e os leva até a fazenda. Nesses locais, dão-lhes ferramentas de trabalho, comida, roupas e um lugar para dormir, todavia isso tem um custo. Nem todos recebem salário, mas, quando recebem, nunca é suficiente para pagar a dívida que só cresce, de modo que o trabalhador se torna refém do patrão. Conforme expõe Nepomuceno,

Quem conhece a armadilha trata de evitá-la. Há também os que se organizam, reivindicam, ocupam terras ociosas. É contra eles que se desata a fúria dos grandes proprietários, legais ou ilegais, de imensas parcelas de terra do Pará. Mas a cada semana continuam chegando braços famintos, e muitos deles deslizam para a armadilha. [...] Muitos tentaram antes a sorte nos garimpos, vagando de déu em déu à procura da salvação dourada. Acabaram de mãos e vida vazias, atraídos pela promessa vã de trabalho nas fazendas e nos empreendimentos agrícolas e pecuários da 
região. Eles são parte da rede de mananciais que fornece braços ao regime da servidão mais absoluta, e também de vidas que, depois de muito perambular, acabam se unindo aos movimentos que reivindicam terra, principalmente ao mais organizado deles, o MST - Movimento dos Trabalhadores Rurais Sem Terra. (Nepomuceno 26-27)

Com esse relato, podemos compreender como o MST vai aumentando, ao passo em que também as dificuldades e as injustiças sociais crescem para essa população. Já a respeito das mortes por causa de terra, o autor revela um estudo que indicou que, entre as décadas de 1980 e 1990, 578 pessoas foram mortas em disputas. "A lista dos ameaçados em todo o Brasil é conhecida e sofre mudanças pontuais: só se sai dela morto" (Nepomuceno $38)$.

Conforme o exposto até aqui, é possível perceber a maneira como a violência, as relações de poder e as questões relacionadas aos Trabalhadores Rurais Sem Terra (MST), no contexto paraense, ganham destaque através da obra $O$ massacre.

O MST está presente em 24 dos 26 Estados brasileiros, tendo representatividade nas cinco regiões do país. Segundo informações oriundas do site oficial do $\mathrm{MST}^{1}$, cerca de 350 mil famílias conquistaram terras através dessa organização e, mesmo depois de assentadas, permanecem no movimento, uma vez que a conquista de terra é somente um dos passos para a realização da Reforma Agrária, grande objetivo do MST.

O Brasil tem uma das maiores concentrações de terras do mundo. "Concentração e improdutividade possuem raízes históricas, que remontam ao início da ocupação portuguesa neste território no século 16" (MST 00). Esse fator, em conjunto com a monocultura de exportação e a escravidão e, ainda, o modo como o país foi ocupado pelos portugueses, gerou uma raiz marcada pela desigualdade social que perdura até a atualidade.

Uma das principais formas para destravar o desenvolvimento econômico e social nos países capitalistas é a democratização do acesso a terra, sendo a reforma agrária uma das principais políticas. No entanto, no Brasil, as transformações políticas para a consolidação do capitalismo não foram suficientes para afrontar a concentração de terras e, ao longo dos séculos, estabeleceram-se lutas e resistências contra a exploração, cativeiro de terra, expropriação e expulsão de trabalhadores. "A resistência camponesa se manifesta em diversas ações e, nessa marcha, participa do processo de transformação da sociedade"

\footnotetext{
${ }^{1} \mathrm{O}$ site do MST pode ser acessado em: https://mst.org.br/.
} 
(MST 00). Desde a década de 1920, foram organizadas formas de luta pela terra e reforma agrária em diferentes regiões do país, sempre marcadas por conflitos. No período da ditadura, o modelo agrário se tornou ainda mais excludente, já que a modernização agrícola passou a ser seletiva, excluindo a pequena agricultura. "O regime militar foi duplamente cruel e violento com os camponeses" (MST 00), já que, como toda a população brasileira, os camponeses foram privados de direitos de expressão e manifestação e, nesse contexto, o êxodo rural foi impulsionado, assim como a exportação e o uso de veneno na produção.

O MST surgiu no final da década de 1970 a partir da expulsão de camponeses e expropriação de diversos trabalhadores rurais. Para ter uma base da dimensão da quantidade de pessoas com a necessidade de busca pela melhoria de vida e por trabalho, Morissawa afirma que, somente com a construção da Hidrelétrica Binacional de Itaipu, no Estado do Paraná, entre os anos de 1975 e 1977, cerca de 12 mil famílias ficaram sem terra e também sem ter onde morar. As lutas do MST são marcadas por conquistas - já que inúmeras famílias conseguem se estabelecer em assentamentos e tirar dali o seu sustento -, mas também são assinaladas por conflitos e dualidades.

Segundo consta no portal do MST, os latifúndios que são utilizados para assentamentos, em geral, possuem pouca infraestrutura, como saneamento, energia elétrica e acesso a lazer e à cultura. Sendo assim, as famílias assentadas continuam organizadas em novas lutas a fim de conquistarem esses direitos, são formados núcleos que discutem as necessidades daquela população, em nível regional, estadual e nacional e, nas assembleias dos acampamentos, todas as pessoas têm direito a voto.

Entretanto, apesar de toda a organização e efetividade positiva do movimento, há também uma parcela desse grupo que se desvia dos ideais propostos pelo MST. O programa de reforma agrária do Governo Federal concede terras consideradas improdutivas para que os camponeses possam produzir alimentos, porém algumas delas são vendidas ilegalmente. Segundo divulgado na imprensa nacional, em alguns desses assentamentos, funcionam empreendimentos como parques aquáticos e pista de motocross. A realidade da venda de terras é exposta na obra de Nepomuceno que explica que os assentados acabavam, em um clima de solidariedade, acolhendo agregados das famílias que não conheciam os projetos do MST, mas tinham esperança de consolidar um futuro. Todavia, quando chegavam, não encontravam terra para trabalhar, apenas hospedagem, porque as terras 
Dossier. Laísa Veroneze Bisol, Xosé Antonio Neira Cruz, Lizandro Carlos Calegari. “O Massacre: a violência representada no jornalismo literário brasileiro"

recebidas não eram o bastante para o trabalho e sustento de todos. Nepomuceno (85) explica: "muitos dos que chegaram depois, atraídos pela família e pela imagem de terras fartas e férteis, acabaram indo buscar trabalho nas fazendas da região", dessa maneira, "rapidamente, transformaram-se em alvo predileto dos que pretendiam fazer do assentamento 17 de Abril um fracasso irremediável".

A situação levava a uma compreensão generalizada de que "ser um sem-terra, em Eldorado, era sinônimo de desocupado, invasor, marginal” (Nepomuceno 99). Esses rótulos, muitas vezes atribuídos de maneira injusta, uma vez que inúmeras pessoas que fazem parte do movimento buscam no trabalho com a terra o sustento de suas famílias, ganham força a partir da atitude de alguns dos sujeitos, o que é representado no romancereportagem:

A partir do final daquele ano [1997], começou - no princípio, um tanto tímido; depois, com maior voracidade - o comércio de lotes. Ou seja: vários dos assentados originais venderam seus lotes, apesar dessa venda ser absolutamente ilegal, a familiares de outros pioneiros que tinham vindo na trilha do sonho da terra. Quem comprou e se instalou - e também os que venderam - repete a mesma explicação: na verdade, o que foi negociado foi o direito à terra. Ou seja: os que, por terem participado da longa luta de reivindicação, receberam terras expropriadas vendem seus direitos sobre elas, e não propriamente as terras. [...] O MST quis impedir a todo custo a implantação desse comércio de terras e não conseguiu. Da mesma forma, não conseguiu impedir a ação dos atravessadores da produção dos assentados, que compravam os produtos para depois vendê-los nos municípios vizinhos com boa margem de lucro. Também não implantou, como estava planejado, o sistema de plena cooperativa para produzir e vender. Aliás, passados mais de dez anos, a comercialização continua sendo um dos problemas do 17 de Abril. (Nepomuceno 86-87)

Os motivos para a venda ilegal seriam, conforme relato expresso na obra, a falta de apoio técnico, de infraestrutura, de financiamento, de máquinas, de facilidade para venda da produção e até falta de organização.

No romance-reportagem $O$ massacre, Nepomuceno destaca que todos esses conflitos causam inúmeras mortes. À exceção de crimes denominados pelo autor como "mais sonoros", ou seja, com o assassinato de pessoas públicas e respaldo midiático, pouca 
ou nenhuma providência é tomada diante de um cenário de injustiça, corrupção e violência que permanece, muitas vezes, no silenciamento, dadas as relações de poder.

A obra representa a violência fazendo relações com o que ocorre em todo o Brasil, mas com foco no Estado do Pará, que se consolidou, conforme o jornalista, como o principal gerador de mortes, uma vez que as disputas e as listas de inimigos têm papel central naquele lugar. "Entre 1994 e 2004, pelo menos 173 pessoas foram assassinadas, outras 501 viveram sob permanente ameaça de morte, e houve pelo menos 837 conflitos violentos entre pistoleiros a serviço dos latifundiários e agricultores" (Nepomuceno, 58). O autor (35) também relata que, “em todo o país, entre 1985 e 2005 foram abertos pelo menos 1.024 processos judiciais por mortes no meio rural brasileiro, sempre em disputas pela posse da terra. Cinquenta por ano, em média: um por semana, ou quase”. Os aspectos mencionados podem ser observados no romance-reportagem em questão:

Em 1996, a participação do Pará no total de trabalhadores rurais assassinados no país alcançou o auge: $72 \%$. Isso se deveu principalmente ao que aconteceu por volta das cinco da tarde na quarta-feira, 17 de abril, quando 155 policiais militares abriram fogo contra 2.500 trabalhadores sem-terra que haviam bloqueado uma estrada nos arredores de Eldorado de Carajás. Quando cessou a metralha, havia 19 mortos e 69 feridos (três deles morreram tempos depois, em consequência dos tiros). (Nepomuceno 58)

O autor da obra esclarece que o ocorrido na data do massacre não se refere apenas a uma postura violenta por parte dos profissionais da linha de frente da polícia, mas de um contexto que envolvia os seus superiores, o próprio Estado e, por fim, os grandes fazendeiros e seus interesses com relação à manutenção de terras. O jornalista argumenta:

Estou convencido, além do mais, de quem são os responsáveis políticos por todas essas mortes. E de que a atuação da Polícia Militar, em especial da tropa sediada em Parauapebas, que agiu com sanha desmedida, foi a trágica consequência de uma tradição que se espalha, muito além do Pará, por todo o interior deste país. Ou seja: as forças da ordem servindo, acima de tudo e em primeiro lugar, a interesses privados. Quem disparou, mutilou e trucidou lavradores sem terra? Soldados, cabos, sargentos e oficiais de uma força policial frequentemente corrompida, bastante mal paga, totalmente despreparada, acostumada muitas vezes a atuar a troco de tostões na defesa dos interesses de fazendeiros, grileiros, ocupantes 
ilegais de terra, pequenos comerciantes. Quem ordenou que essa força policial, com tantas características fartamente conhecidas, desobstruísse, ao preço que fosse, uma estrada bloqueada pelos sem-terra? O governo estadual, integrado por representantes de um sistema que há décadas é dominado, com nuances sazonais, pelos mesmos grupos e pelos mesmos interesses no estado do Pará. (Nepomuceno 17)

Conforme o exposto, fica nítida a relação da violência representada na narrativa com os poderes. Estão expostos o poder coercitivo, considerando que se utiliza da força física e armada, o poder político, já que o recurso da autoridade implica uma ação que, nesse caso, também se interliga com o poder econômico, uma vez que grandes fazendeiros se posicionam contra o movimento. Esses mesmos fazendeiros inclusive solicitam às autoridades medidas efetivas tendo em vista que os manifestantes bloqueavam a rodovia. Embora os integrantes do MST também dispusessem da violência em alguns momentos, a desproporcionalidade das ações fica evidente a partir das diferenças de poder.

Por exemplo, no dia do massacre, conforme relata Nepomuceno, segundo os militantes, do lado do MST, havia três revólveres, uma garrucha, foices, facões, enxadas e garrafas explosivas, sendo que nenhuma delas chegou a ser lançada contra a Polícia Militar. No entanto, no inquérito policial pós-conflito, a PM entregou, como sendo armas do MST, dez revólveres de calibre 38, três de calibre 32, uma garrucha, uma outra de fabricação caseira, e 17 espingardas que, segundo líderes do movimento, jamais estiveram sob sua posse. Independentemente da discussão sobre qual dos dois grupos têm a verdade com relação ao exposto, de alguma maneira, fica claro, com o resultado do episódio do confronto e com o histórico de violência contra esses indivíduos, que o lado mais fraco diz respeito aos integrantes do MST. Conforme Nepomuceno (49), "no cruzamento dos destinos daqueles que querem terra para trabalhar e dos que a querem para a exploração desenfreada, perde sempre a parte mais fraca".

O modo como os integrantes do MST foram humilhados no dia do massacre é descrito pelo jornalista de maneira detalhada, com atribuição não somente da identidade, mas também dos sentimentos que circundavam as pessoas que presenciaram aquele instante. Uma dessas descrições pode ser observada a seguir:

No meio do caos, um homem avançou, gesticulando muito, contra os policiais militares. Foi tombado por um soldado, que o golpeou na cabeça 
com um cassetete. No chão, foi chutado por outros soldados. E, tombado, ao tentar se erguer, levou três tiros - um na cabeça, outro debaixo do braço, um terceiro na linha da cintura. Esse homem chamava-se Amâncio Rodrigues dos Santos, tinha 42 anos e era surdo. Certamente, não ouviu nem os pedidos de Oziel Alves Pereira para que os sem-terra resistissem à ação da polícia militar, nem as ordens dos soldados mandando todos correr. Foi a primeira vítima. (Nepomuceno 155)

O autor explica que, a partir da primeira vítima, o que ocorreu, durante aproximadamente 40 minutos, foi um massacre violento com alvos determinados, já que não havia outra explicação para o porquê de, em meio a tantos envolvidos, contando com mulheres e crianças, somente homens terem sido mortos. O que aconteceu com Amâncio demonstra a prática de um ato que não é somente violento e humilhante, mas cruel, evidenciando o quanto não havia nenhuma sensibilidade por parte daqueles que estavam dispostos a executarem o plano para aquela tarde. Assim como esse, muitos outros trechos do livro apresentam os indivíduos e o modo como foram agredidos ou mortos no dia 17 de abril de 1996, sempre acrescidos de seus nomes e de análises acerca do que sofreram.

Esse modo de narrar se difere bastante do que vemos na mídia tradicional, em que, normalmente, assassinatos ou tragédias são expostos de forma genérica, apontando o número de vítimas e não abrangendo seus sentimentos. Aquelas mídias que tentam fazer isso, muitas vezes, acabam explorando um viés sensacionalista, mais voltado à exposição das emoções alheias em busca de audiência do que, necessariamente, abarcando uma crítica social. Tendo em vista a imbricação entre os poderes que se unem para o estabelecimento da crueldade, cabe retomar os tipos de violência que identificamos representadas na obra $O$ massacre, sendo elas: física, psicológica, vingativa, compensatória e intencional.

A violência física fica evidenciada no trecho exposto anteriormente e se reafirma ao observarmos a quantia de mortos e feridos oriundos do confronto representado no romancereportagem. A psicológica pode atuar também como consequência da primeira, ao observarmos o seguinte trecho de Nepomuceno (18): "Quem morreu, foi ferido, ficou mutilado - no corpo e na alma - para sempre?". Ao falar sobre o sofrimento da "alma", é possível compreender que as marcas da violência ultrapassam as dores físicas. Uma das formas de demonstrar esses aspectos, na obra, é a partir da narrativa das histórias pessoais de sobreviventes. Ao atribuir nome a um sem-terra, informando o modo como ele mesmo conta a sua história, o autor do romance-reportagem não somente humaniza a classe desses 
Dossier. Laísa Veroneze Bisol, Xosé Antonio Neira Cruz, Lizandro Carlos Calegari. “O Massacre: a violência representada no jornalismo literário brasileiro"

trabalhadores rurais, como demonstra de modo muito profundo como a violência interage com esses indivíduos.

Uma das histórias mencionadas é a de Inácio Pereira, de 56 anos, na época. O manifestante foi considerado como morto pelos policiais e foi atirado em uma caminhonete que carregava 18 cadáveres. Entre os corpos, estava o de seu filho Raimundo. O autor demonstra como a violência psicológica fez parte desse episódio atrelada à física:

Derrubado por policiais no meio do tumulto de tiros, gritos, bombas e pancadas, foi pisoteado, chutado um sem-fim de vezes e ficou no chão feito morto, em silêncio, sem se mexer. [...] Agarrado pelos braços, foi arrastado pelo chão e jogado em cima de cadáveres na caçamba da caminhonete. O corpo morto do filho estava embaixo. Não se tocaram. Em cima dele foi atirado outro homem - supostamente, outro corpo morto. Inácio continuou num silêncio de pavor e ouviu que, em cima dele, o homem gemia e dizia coisas sem sentido. A cabeça desse homem pendeu sobre o pescoço de Inácio, que não conseguia entender o que ele sussurrava entre os gemidos. (Nepomuceno 108)

Embora, naquele momento, Inácio não soubesse que seu filho morto estava dividindo o mesmo espaço, pouco tempo depois, a informação chegou e ficou registrada na memória, ampliando sua dor, que é representada através do livro. O autor também expõe que já à noite os 19 mortos foram levados para o Instituto Médico Legal (IML) há mais ou menos 140 quilômetros de distância.

Nepomuceno expõe os atos violentos daquela ocasião de maneira bastante detalhada, a partir de toda a sua pesquisa e das entrevistas com os envolvidos, e também demonstra as suas percepções, conforme exposto a seguir:

Cheguei à conviç̧ão de que o que aconteceu na tarde da quarta-feira, dia 17 de abril de 1996, no trecho da rodovia PA-150 - a principal do sudeste do Pará e uma das principais do estado - conhecido como Curva do S, a escassos quilômetros de Eldorado do Carajás, foi uma das mais frias e emblemáticas matanças da história contemporânea do país. Ninguém deveria sequer se atrever a usar palavras como "confronto", "incidente" ou "choque" para descrever o que aconteceu na Curva do S. Aquilo foi uma carnificina brutal, um massacre que permanece impune. [...] Tenho plena convicção de que ao menos dez das 19 pessoas que caíram no dia 17 de abril de 1996 foram mortas a sangue-frio, quando já se encontravam submetidas pela Polícia Militar ou tinham sido feridas e não 
puderam fugir. As fotos que ilustram os laudos periciais dos cadáveres são um primor de barbárie: corpos mutilados, cabeças destroçadas. Foi como se não bastasse disparar contra alguém desarmado: era preciso mais. Era preciso desafogar uma fúria descontrolada e estabelecer de uma vez e para sempre qual era a punição que iriam além da morte. (Nepomuceno 16)

Esse trecho demonstra o quanto cada tipo de violência fez parte da situação representada, ficando evidenciadas a violência física e, principalmente, a intencional, uma vez que o autor faz menção ao ocorrido como algo que vai além de um confronto ou incidente, deixando a ideia notória de que as mortes e ferimentos causados naquele dia fizeram parte da motivação de indivíduos que agiram de modo violento de maneira consciente.

A violência tipificada como "vingativa" também está representada na obra. Essa forma de crueldade diz respeito à realização de atos violentos como uma tentativa de retribuir um sofrimento, a partir de uma punição. Esse conceito é aplicável ao contexto exposto, tendo em vista que segmentos sociais como os grandes fazendeiros e, talvez por consequência, o próprio poder público, são confrontados com as reivindicações dos integrantes do MST. Também não se pode dizer que uma parcela desse grupo não atue de modo violento, o que gera um sentimento de violência justificável por parte daqueles que detêm o poder.

Nepomuceno (34) descreve que é praticamente impossível indicar um número exato a respeito da quantia de pessoas mortas no Brasil anualmente por reclamarem terra e incomodarem indivíduos poderosos. Segundo ele, "essa enxurrada de números chega a marear, mas cada cifra, cada estatística, torna-se essencial para uma visão aproximada do grau de brutalidade e devastação registrado no Pará". O autor explica que aqueles que incomodam os poderosos estão em uma lista, e fazem parte dela líderes do Movimento, ativistas e até mesmo religiosos que expõem seu pensamento em defesa dos menos favorecidos. Existem, então, aqueles que são contratados para realizarem as execuções e, a partir disso, define-se uma tabela de preços para as mortes. Um político, por exemplo, pode custar bem caro. Há também indícios da existência de consórcios com uma reserva para pagar pistoleiros para matar lideranças incômodas: 
Esses consórcios seriam integrados por fazendeiros, exploradores ilegais de madeira, usurpadores de terras públicas. Existiriam também as milícias, grupos que trabalham como segurança de grandes fazendas e empresas, formadas por policiais militares ou ex-integrantes da PM. E, finalmente, as empresas de segurança - encobertas por véus de legalidade, com registro formal. (Nepomuceno 41)

O autor destaca que uma dessas empresas de segurança possuía como um dos donos o Secretário de Segurança do Pará, na época. Era, também, a empresa responsável por assegurar a Companhia Vale do Rio Doce. Apesar dessas informações adicionais, que podem ou não se tratar de coincidências, segundo enfatiza o jornalista, importa observarmos que a questão da vingança está muito presente nas justificativas para a violência e são muitos os grupos envolvidos em possíveis planos de extinguir aqueles que incomodam os detentores do poder. Perceber essas questões nos instiga a retomar o pensamento de Ginzburg a respeito dos questionamentos acerca da violência como não justificável. Ainda na perspectiva desse autor, retomo a ideia abordada anteriormente sobre o quanto a violência já está naturalizada no Brasil. Esse aspecto também está presente no romance-reportagem analisado:

Nas duas pontas - quem mandou, quem executou -, a dramática reedição de um hábito enraizado no que há de pior das tradições brasileiras: a justiça feita pelas próprias mãos, a mando e na defesa dos interesses de determinados grupos e, às margens da Justiça. A imposição absoluta da lei e da ordem - determinada lei, jamais escrita, e determinada ordem, cujos limites e parâmetros ninguém, a não ser os que as impõem, conhece. A inexistência, enfim, de uma linha clara que separe o que é público do que é privado: recorre-se à força policial como quem recorre a uma milícia particular. (Nepomuceno18, grifos do autor)

A problemática levantada na narrativa diz respeito a uma mistura de poderes, uma vez que as lideranças políticas e as forças policiais deveriam estar, por obviedade, a serviço de toda a população, no entanto acabam, por vezes, sendo vencidos pela pressão daqueles que, por interesses particulares, detêm não somente o poder com relação aos seus bens, mas, muitas vezes, para modificar realidades que prejudicam os seus projetos particulares. A respeito disso, Chaui (39) trata a respeito de uma "imagem unificada da violência”. Descreve que "chacina, massacre, vandalismo, guerra civil tácita, indistinção 
entre polícia e crime e desordem pretendem ser o lugar onde a violência se situa e se realiza". Sendo assim, a estudiosa explica que a limitação da sociedade civil e a debilidade das instituições políticas são postas como impotentes na coibição da violência. “O conjunto dessas imagens indica a divisão entre dois grupos: de um lado, estão os grupos dos portadores de violência, e, de outro, os grupos dos impotentes para combatêla" (grifos da autora).

Ao refletir sobre esse aspecto da impotência no combate a ações de crueldade, é oportuno fazer a associação com a violência compensatória que diz respeito àquela em que, para compensar uma debilidade diante do mundo ou de ocasiões específicas, os sujeitos cometem a violência, não porque querem, de fato, causar sofrimento, mas a fim de exercerem domínio sobre outras pessoas. Essa definição está em consonância com a ideia de que aqueles que estão na linha de frente, cumprindo ordens, podem também ser postos como vítimas diante de outros contextos da vida. Isso está representado no livro $O$ massacre, por exemplo, a partir do depoimento de Raimundo Gouvêa. O assentado era, na época do relato, um dos dirigentes do MST procurados na região, já que seu nome constava na lista dos fazendeiros entregue à Polícia Militar, pois indicava as lideranças perigosas do Movimento. Ele conta, em depoimento, que muitas vezes queria voltar para casa com comida para os filhos, mas isso não era possível; por vezes, ganhava cestas básicas com alimentos estragados e lembra a humilhação: “'O pior', diz ele, 'é que os que nos maltratavam eram pobres que nem a gente, desgraçados que nem a gente, humilhados que nem nós, e ainda assim humilhavam a gente"” (Nepomuceno, 99). A partir do exposto, compreendemos que não somente a violência como também a vulnerabilidade diante das relações de poder são estruturais no país, reiterando a ideia de que os poderes se invertem, em determinados momentos, mas que, sobretudo, há classes que sempre serão marginalizadas diante dessa violência, sofrendo as consequências da crueldade em maior ou menor grau.

\section{Algumas considerações}

Com o estudo de $O$ massacre, foi possível identificar que a violência está representada na obra em suas diversas facetas, seja de cunho físico, psicológico, vingativo, compensatório ou intencional. 
Dossier. Laísa Veroneze Bisol, Xosé Antonio Neira Cruz, Lizandro Carlos Calegari. “O Massacre: a violência representada no jornalismo literário brasileiro"

Reiteramos que a violência apresentada a partir da narrativa está intimamente relacionada aos poderes coercitivo, simbólico e político, mas, mais do que isso, não é apenas a economia ou interesses privados que tornam o Pará uma terra sem cumprimento da lei, mas, sim, uma necessidade de inferiorizar hierarquicamente uma classe que busca por direitos não reconhecidos pela população e, com isso, é gerada a ideia de humilhação.

Conforme foi possível identificar em $O$ massacre, há um caminho muito longo para que o poder político se alie às buscas do Movimento. Embora alguns integrantes do MST também pratiquem ações violentas e muitos acabam desvirtuando os ideais para os quais o Movimento existe, em sua essência, trata-se de um coletivo que busca, por fim, a justiça, difícil de ser cumprida se os principais poderes do país não compreendem e não buscam compreender essas verdades.

A vulnerabilidade e o sofrimento causado pelas contrariedades que permeiam esse grupo e perpassam todo o romance-reportagem promove a representatividade dos sujeitos. Ao longo da narrativa, eles deixam de ser números e passam a ter seus nomes e histórias contadas, o que contribui não somente para a constituição de um documento que revela pormenores do massacre ocorrido em 1996, mas, sobretudo, do drama enfrentado por uma classe brasileira que tem sua imagem comumente distorcida pela percepção popular.

Conforme o pesquisador Jorge Kanehide Ijuim, o jornalismo pode buscar humanizar por meio das narrativas, quando esses relatos não caricaturizam os seres humanos, mas, ao invés disso, levam à discussão da problemática sem apontar as pessoas como sendo meras peças de um fenômeno social, discutindo a respeito das causas e dos contextos que as circundam. Ademais, ao escrever com viés no enfrentamento da violência, o autor da obra em questão não ignora a complexidade dos acontecimentos, pelo contrário, os expõe com detalhamento e com o foco de dissolver os pensamentos discriminatórios e preconceituosos.

Embora o fenômeno da violência seja tido como entronizado no cenário do país, causando inclusive senso de normalidade, o jornalismo literário brasileiro pode assumir um importante papel que vai na contramão dessa perspectiva. Foi possível observar, a partir da obra analisada, que o discurso pode estar voltado a criticar, contextualizar, denunciar e evidenciar as questões críticas que acometem especialmente alguns determinados grupos sociais no país. 


\section{REFERÊNCIAS}

Arendt, Hannah. Da violência. UNB, 1985.

Bastos, Aguinaldo de, Alexandre Marques Cabral e Jonas Rezende. Ontologia da violência: o enigma da crueldade. Mauad X, 2010.

Chaui, Marilena. Sobre a violência, org. Ericka Marie Itokazu e Luciana Chaui-Berlinck. Autêntica Editora, 2018.

Chillón, Albert. Literatura y periodismo: una tradición de relaciones promiscuas. Servei de Publicaciones, 1999.

Freud. Sigmund. "Documento $n^{\circ}$ 2: resposta de Sigmund Freud à Albert Einstein. 1932. Um diálogo entre Einsten e Freud: por que a guerra?, apresentação de Deisy de Freitas Lima Ventura e Antônio Silva Ricardo Seitenfus. Fadisma, 2005. p. 27-47. http://library.fes.de/pdf-files/bueros/brasilien/05620.pdf. Acesso em 04 set. 2018.

Foucault, Michel. Ditos e escritos II. Rio de Janeiro: Forense Universitária, 2002.

Ginzburg, Jaime. Literatura, violência e melancolia. Autores Associados, 2013.

Ijuim, Jorge Kanehide. "Por que humanizar o jornalismo (?)". Verso e Reverso, v. 31, n. 78, p. 235-243, 2017. http://revistas.unisinos.br/index.php/versoereverso/article/ viewFile/ver.2017.31.78.07/6252. Acesso em 19 abr. 2018.

Lima, Edvaldo Pereira. O que é livro-reportagem. Brasiliense, 1998.

Morissawa, M. A história da luta pela terra e o MST. Expressão Popular, 2001.

Nepomuceno, Eric. O massacre: Eldorado dos Carajás: uma história de impunidade. Planeta, 2007.

Pena, Felipe. Jornalismo literário. Contexto, 2008.

Thompson, John B. A mídia e a modernidade: uma teoria social da mídia, tradução de Wagner de Oliveira Brandão, revisão da tradução Leonardo Avritzer. 15. ed. Vozes, 2014.

Wolfe, Tom. Radical e chique e o Novo Jornalismo, tradução de José Rubens Siqueira. 2. ed. Companhia das Letras, 2005.

Žižek. Slavoj. Violência: seis reflexões laterais, tradução de Miguel Serras Pereira. Boitempo, 2014. 